\title{
Production of high-content galacto-oligosaccharide by enzyme catalysis and fermentation with Kluyveromyces marxianus
}

\author{
Chao-Chun Cheng • Mei-Ching Yu • \\ Tzu-Chien Cheng · Dey-Chyi Sheu • \\ Kow-Jen Duan - Wei-Lun Tai
}

Published online: 28 September 2006

(C) Springer Science+Business Media B.V. 2006

\section{Erratum to: Biotechnol Lett (2006) 28: 793-797 DOI 10.1007/s10529-006-9002-1}

In Table 1 of the original the values in the row showing Reaction temperature and time were incorrectly placed. The correct Table 1 is shown overleaf.

The online version of the original article can be found at http://dx.doi.org/10.1007/s10529-006-9002-1

C.-C. Cheng · D.-C. Sheu $(\bowtie) \cdot$ K.-J. Duan ·

W.-L. Tai

Department of Bioengineering, Tatung University,

Taipei 104, Taiwan

e-mail: dcsheu@ttu.edu.tw

\section{M.-C. Yu}

Department of Chemical Engineering, Tatung

University, Taipei 104, Taiwan

T.-C. Cheng

Department of Chemical Engineering, Northern

Taiwan Institute of Science and Technology, Taipei

112, Taiwan 
Table 1 Comparison of low-content GOS produced by three $\beta$-galactosidases under various conditions. The results were obtained from duplicated experiments

\begin{tabular}{|c|c|c|c|c|c|c|c|c|c|}
\hline \multicolumn{2}{|l|}{ Source of enzyme } & \multicolumn{2}{|l|}{ A. oryzae } & \multicolumn{2}{|l|}{ K. lactis } & \multicolumn{4}{|c|}{ Bacillus sp. } \\
\hline Enzyme dose per g lactose & $(\mathrm{U})$ & 6.2 & 6.2 & 13 & 10 & 4.5 & 4.5 & 5.6 & 5.6 \\
\hline Reaction temperature and time & & $30^{\circ} \mathrm{C} 5 \mathrm{~h}$ & $50^{\circ} \mathrm{C} 5 \mathrm{~h}$ & $30^{\circ} \mathrm{C} 3 \mathrm{~h}$ & $40^{\circ} \mathrm{C} 3 \mathrm{~h}$ & $50^{\circ} \mathrm{C} 3 \mathrm{~h}$ & $50^{\circ} \mathrm{C} 5 \mathrm{~h}$ & $50^{\circ} \mathrm{C} 3 \mathrm{~h}$ & $50^{\circ} \mathrm{C} 5 \mathrm{~h}$ \\
\hline Total GOS & $\left(\mathrm{g} \mathrm{l}^{-1}\right)$ & 53.5 & 70.4 & 71.3 & 116.6 & 91.6 & 108.2 & 110.2 & 110.6 \\
\hline GOS-2 & & - & - & $(42.2)$ & $(74.9)$ & $(10.3)$ & $(14.6)$ & $(18.4)$ & $(32.9)$ \\
\hline GOS-3 & & $(53.5)$ & $(70.4)$ & $(29.1)$ & $(41.6)$ & $(71.0)$ & $(79.5)$ & $(73.0)$ & $(62.5)$ \\
\hline GOS-4 & & - & - & - & - & $(10.3)$ & $(14.0)$ & (18.8) & $(15.0)$ \\
\hline Glucose & & 34.8 & 42.8 & 92.0 & 78.7 & 33.3 & 43.0 & 54.4 & 84.6 \\
\hline Galactose & & 13.9 & 17.4 & 46.6 & 53.1 & 8.4 & 11.1 & 18.1 & 20.2 \\
\hline Lactose & & 227.6 & 199.3 & 120.0 & 81.5 & 196.6 & 167.5 & 146.1 & 114.4 \\
\hline Conversion rate $^{\mathrm{a}}$ & $(\%)$ & 52 & 54 & 34 & 47 & 69 & 67 & 60 & 51 \\
\hline Yield $^{\mathrm{b}}$ & $(\%)$ & 16 & 21 & 22 & 35 & 28 & 33 & 33 & 34 \\
\hline
\end{tabular}

${ }^{a}$ mass ratio of GOS to the consumed lactose

b mass ratio of GOS to the initial lactose 